\title{
Neonatal resuscitation adhering to oxygen saturation guidelines in asphyxiated lambs with meconium aspiration
}

\author{
Munmun Rawat ${ }^{1}$, Praveen K. Chandrasekharan', Daniel D. Swartz ${ }^{1,2}$, Bobby Mathew ${ }^{1}$, Jayasree Nair', \\ Sylvia F. Gugino ${ }^{1,2}$, Carmon Koenigsknecht ${ }^{1}$, Payam Vali' and Satyan Lakshminrusimha'
}

BACKGROUND: The Neonatal Resuscitation Program (NRP) recommends upper and lower limits of preductal saturations $\left(\mathrm{SpO}_{2}\right)$ extrapolated from studies in infants resuscitated in room air. These limits have not been validated in asphyxia and lung disease.

METHODS: Seven control term lambs delivered by cesarean section were ventilated with $21 \% \mathrm{O}_{2}$. Thirty lambs with asphyxia with meconium aspiration were randomly assigned to resuscitation with $21 \% \mathrm{O}_{2}(n=6), 100 \% \mathrm{O}_{2}(n=6)$, or initiation with $21 \% \mathrm{O}_{2}$ followed by variable $\mathrm{FIO}_{2}$ to maintain NRP target $\mathrm{SpO}_{2}$ ranges $(n=18)$. Hemodynamic and ventilation parameters were recorded for $15 \mathrm{~min}$.

RESULTS: Control lambs maintained preductal $\mathrm{SpO}_{2}$ near the lower limit of NRP target range. Asphyxiated lambs had low $\mathrm{SpO}_{2}(38 \pm 2 \%)$, low arterial pH (6.99 \pm 0.01$)$, and high $\mathrm{PaCO}_{2}$ $(96 \pm 7 \mathrm{~mm} \mathrm{Hg})$ at birth. Resuscitation with $21 \% \mathrm{O}_{2}$ resulted in $\mathrm{SpO}_{2}$ values below the target range with low pulmonary blood flow (Qp) compared to variable $\mathrm{FlO}_{2}$ group. The increase in $\mathrm{PaO}_{2}$ and $\mathrm{Qp}$ with variable $\mathrm{FIO}_{2}$ resuscitation was similar to control lambs.

CONCLUSION: Maintaining $\mathrm{SpO}_{2}$ as recommended by NRP by actively adjusting inspired $\mathrm{O}_{2}$ leads to effective oxygenation and higher Qp in asphyxiated lambs with lung disease. Our findings support the current NRP $\mathrm{SpO}_{2}$ guidelines for $\mathrm{O}_{2}$ supplementation during resuscitation of an asphyxiated neonate.

$\mathbf{T}$ he use of $100 \%$ oxygen was routine during resuscitation of newly born infants (1) prior to the 2010 Neonatal Resuscitation Program (NRP) guidelines (2-4). Pulse oximetry studies of healthy term and preterm infants who did not require resuscitation at birth demonstrated that preductal oxygen saturation $\left(\mathrm{SpO}_{2}\right)$ is $~ 60 \%$ at birth and takes $5-10 \mathrm{~min}$ to reach $85-90 \%$ (5). The percentiles of $\mathrm{SpO}_{2}$ at each minute of life have been identified and the goal saturation range has been approximately defined as interquartile ranges for healthy term infants (3). Current guidelines recommend starting resuscitation with $21 \%$ oxygen in term infants. Oxygen supplementation is then guided by preductal $\mathrm{SpO}_{2}$ and adjusted to maintain
$\mathrm{SpO}_{2}$ values in the goal saturation range at the corresponding minute of postnatal life $(3,6,7)$.

However, it is important to recognize that infants with asphyxia or lung disease who needed resuscitation were excluded from these studies. Asphyxia results in hypoxemia and acidosis (8) resulting in lower $\mathrm{SpO}_{2}$ values at the time of birth (9). Furthermore, in the presence of lung disease (such as meconium aspiration) and increased alveolar-arterial oxygen gradient, $21 \%$ inspired oxygen may not be sufficient to achieve the target $\mathrm{SpO}_{2}$ values recommended by the NRP. Also, the combination of asphyxia and lung disease predisposes infants to persistent pulmonary hypertension of the newborn (10) that can lead to intra- and extrapulmonary right-to-left shunting of blood, further decreasing $\mathrm{SpO}_{2}$ (11). The effect of maintaining preductal $\mathrm{SpO}_{2}$ in the reference goal range recommended by the NRP on hemodynamics and gas exchange in the presence of perinatal asphyxia and lung disease is not known. Controversy remains as to whether a lower percentile $\mathrm{SpO}_{2}$ target (that can potentially be achieved with $21 \%$ inspired oxygen) might be as effective and potentially safer in asphyxiated neonates (12).

The aim of our study was to evaluate gas exchange and pulmonary/cerebral hemodynamics during resuscitation in an ovine model of perinatal asphyxia (induced by umbilical cord occlusion) and lung disease (through instillation of meconium through the endotracheal tube) (9) adhering to the current NRP oxygen saturation target guidelines. We compared these results with lambs resuscitated with 21 and $100 \%$ inspired oxygen. We hypothesize that adjusting inspired oxygen to achieve goal NRP $\mathrm{SpO}_{2}$ range in asphyxiated lambs with lung disease and persistent pulmonary hypertension of the newborn will result in hemodynamics and gas exchange similar to that observed in control lambs (without asphyxia or lung disease) ventilated with $21 \% \mathrm{O}_{2}$ at birth.

\section{RESULTS}

Thirty lambs were randomized, instrumented, asphyxiated, and delivered. Eighteen lambs were randomized to the variable $\mathrm{FIO}_{2}$ group to keep preductal $\mathrm{SpO}_{2}$ between 60 and $85 \%$ for the first $15 \mathrm{~min}$ after birth and six lambs each were randomized to

'Department of Pediatrics, University at Buffalo, Buffalo, New York; ${ }^{2}$ Department of Physiology and Biophysics, University at Buffalo, Buffalo, New York. 


\section{Articles | Rawate al.}

receive inspired oxygen of 100 or $21 \%$ irrespective of $\mathrm{SpO}_{2}$. To generate control data, seven healthy term lambs were ventilated with $21 \% \mathrm{O}_{2}$. Gestational age, birth weight, and gender distribution were similar among the groups. None of the animals required chest compressions or epinephrine. The gender distribution was equal (15 male and 15 female lambs) and no significant hemodynamic or gas exchange differences were observed between the genders.

\section{Oxygenation}

Asphyxia by umbilical cord occlusion resulted in a significant decrease in preductal $\mathrm{SpO}_{2}$ compared to the control group ( $38 \pm 2$ vs. $53 \pm 1.4 \%$, respectively). Control lambs ventilated with $21 \% \mathrm{O}_{2}$ maintained preductal $\mathrm{SpO}_{2}$ in the target range recommended by NRP (Figure 1). Asphyxiated lambs randomized to 21 and $100 \%$ inspired oxygen had $\mathrm{SpO}_{2}$ values below and above the NRP target range, respectively. By design, asphyxiated lambs ventilated with variable $\mathrm{FIO}_{2}$ maintained their $\mathrm{SpO}_{2}$ values within the target range (Figure 1) but this required frequent titration of $\mathrm{FIO}_{2}$ (Figure 2). Baseline fetal oxygen was similar in all the groups $(23 \pm 8 \mathrm{~mm} \mathrm{Hg})$. However, after meconium instillation and cord occlusion, the $\mathrm{PaO}_{2}$ dropped significantly in asphyxiated lambs $(15 \pm 12 \mathrm{~mm} \mathrm{Hg})$ but improved with resuscitation and positive pressure ventilation (Figure 3a). The lambs that were ventilated with $100 \%$ inspired oxygen had significantly higher $\mathrm{PaO}_{2}$ from birth until 15 min when compared to the other three groups (Figure 3a).

\section{Arterial pH}

Predelivery arterial $\mathrm{pH}$ was lower in the three asphyxiated groups $(6.99 \pm 0.01)$ when compared to controls $(7.29 \pm 0.09)$.
Asphyxiated lambs ventilated with $100 \%$ inspired $\mathrm{O}_{2}$ had significantly higher $\mathrm{pH}$ throughout the $15 \mathrm{~min}$ of resuscitation when compared to the lambs ventilated with variable $\mathrm{FIO}_{2}$ (Figure 3b). However, there was no difference in the base deficit between the two asphyxiated groups ( $-6 \pm 3.8$ in $100 \%$ inspired oxygen vs. $-7.9 \pm 2$ in variable $\mathrm{FIO}_{2}$ ).

\section{Ventilation}

Predelivery $\mathrm{PaCO}_{2}$ was similar in the three asphyxiated groups $(96 \pm 7 \mathrm{~mm} \mathrm{Hg})$ at the onset of ventilation and was significantly higher than controls $(56 \pm 9.5 \mathrm{~mm} \mathrm{Hg})$. No significant difference was noted in $\mathrm{PaCO}_{2}$ among asphyxiated lambs (Figure 3c). There was no difference between the ventilator rate and mean airway pressures among the three asphyxiated groups.

\section{Systemic Hemodynamics}

Baseline heart rate (HR) was similar among all the groups $(154 \pm 23 / \mathrm{min})$ but umbilical cord occlusion caused significant bradycardia in the three asphyxiated groups $(83 \pm 37 /$ $\mathrm{min}$ ). With resuscitation by positive pressure ventilation, the HR for the first $15 \mathrm{~min}$ was similar between the asphyxiated lambs ventilated with variable $\mathrm{FIO}_{2}$ and controls (Figure 4). Baseline fetal mean systemic blood pressure was similar among all the groups $(47 \pm 2.7 \mathrm{~mm} \mathrm{Hg})$. Mean systemic blood pressure in the three asphyxiated groups $(52 \pm 4.7 \mathrm{~mm}$ $\mathrm{Hg}$ ) was significantly lower than the controls $(71 \pm 16.2 \mathrm{~mm}$ $\mathrm{Hg}$ ) over the period of $15 \mathrm{~min}$ (Figure 5a). Left carotid blood flow was similar among all the groups $(23.6 \pm 2.27 \mathrm{ml} / \mathrm{kg}$ / $\mathrm{min}$ in asphyxiated group vs. $26.3 \pm 2 \mathrm{ml} / \mathrm{kg} / \mathrm{min}$ in controls) (Figure 6a).

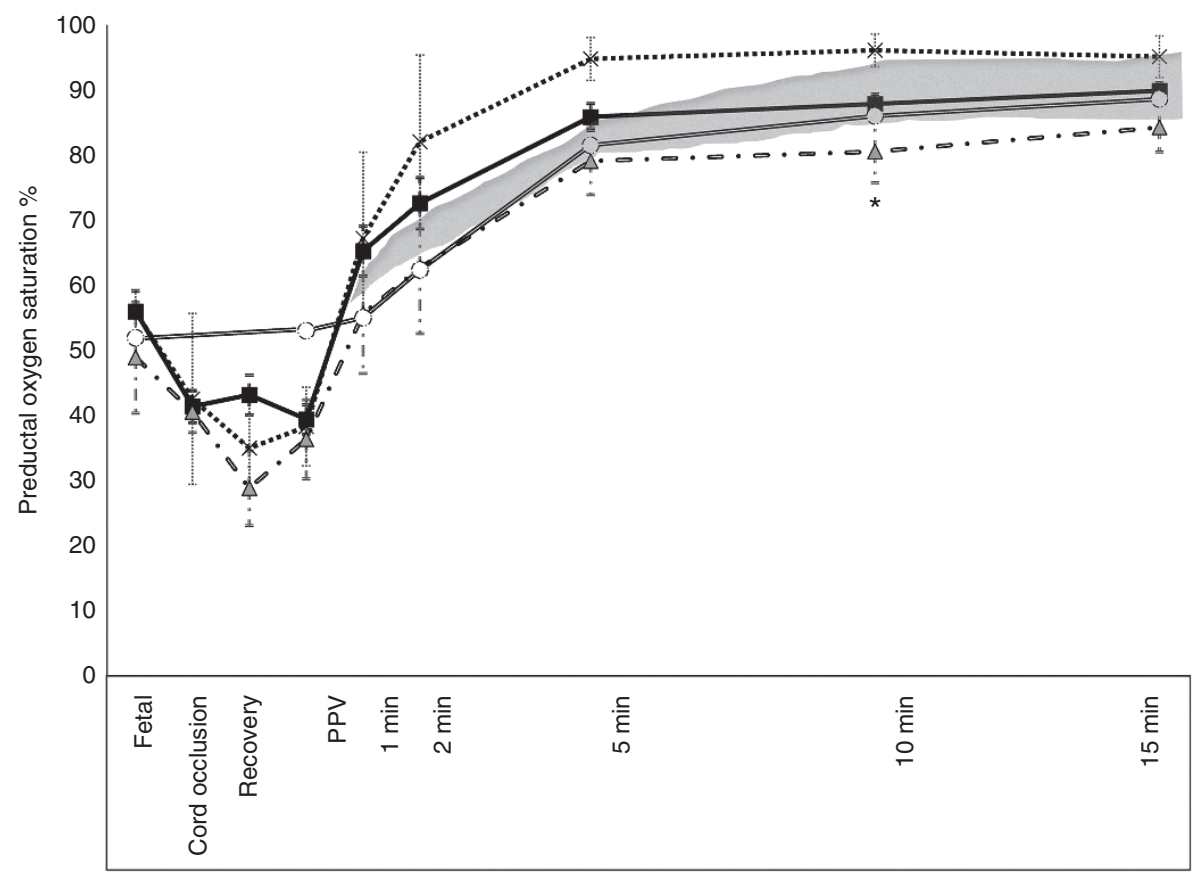

Figure 1. Changes in preductal oxygen saturation $\left(\mathrm{SpO}_{2}\right)$ during fetal life and the first 15 min of postnatal age in control lambs (open circle) and asphyxiated term lambs ventilated with $21 \% \mathrm{O}_{2}$ (gray triangle), $100 \% \mathrm{O}_{2}$ (cross), and inspired oxygen ( $\mathrm{FIO}_{2}$ ) titrated to keep the $\mathrm{SpO}$ as per $\mathrm{Neonatal}$ Resuscitation Program (NRP) guidelines (black square). The shaded area represents the oxygen saturation range recommended by NRP. * $P<0.05$ at 10 min time point by ANOVA ( $21 \%$ asphyxia and $100 \%$ asphyxia significantly different by Bonferroni post hoc test). PPV, positive pressure ventilation. 


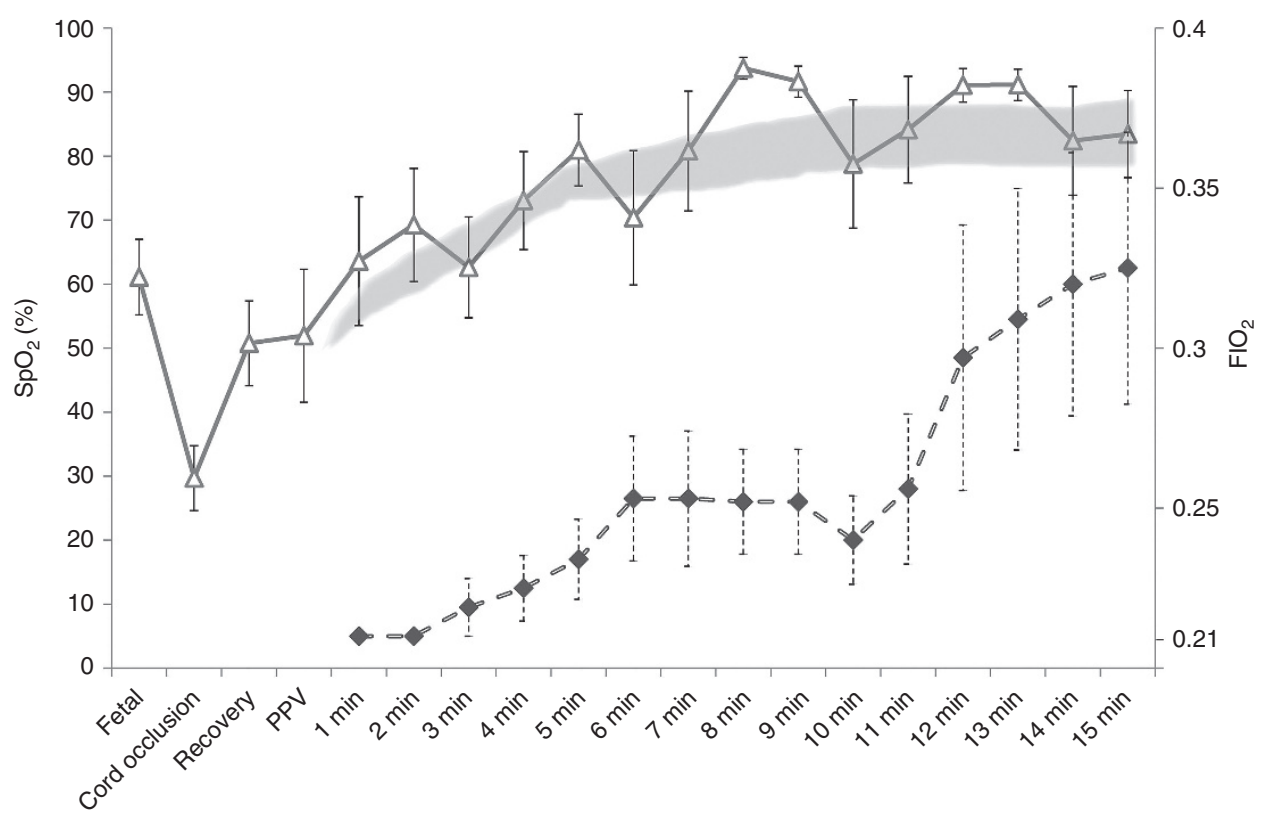

Figure 2. Titration of fraction of inspired oxygen $\left(\mathrm{FlO}_{2^{\prime}}\right.$ closed diamond) to maintain the preductal saturation ( $\mathrm{SpO}_{2^{\prime}}$ open triangle) between 85 and $95 \%$. The $\mathrm{X}$-axis represents fetal life, asphyxiation and resuscitation, and postnatal life in minutes. PPV, positive pressure ventilation.

\section{Pulmonary Hemodynamics}

Pulmonary blood flow (Qp) was significantly lower in the asphyxiated $21 \%$ inspired oxygen group $(42.3 \pm 17 \mathrm{ml} / \mathrm{kg} / \mathrm{min})$ compared to variable $\mathrm{FIO}_{2}(65.8 \pm 10 \mathrm{ml} / \mathrm{kg} / \mathrm{min})$ and asphyxiated $100 \%$ group $(64.1 \pm 13 \mathrm{ml} / \mathrm{kg} / \mathrm{min})$ (Figure $6 \mathrm{~b})$. Interestingly, variable $\mathrm{FIO}_{2}$ group had higher Qp than controls $(51.4 \pm 5 \mathrm{ml} / \mathrm{kg} /$ min). Mean pulmonary artery pressure was higher in asphyxiated lambs ventilated with variable $\mathrm{FIO}_{2}$ group $(51 \pm 3.4 \mathrm{~mm}$ $\mathrm{Hg}$ ) when compared to asphyxiated lambs ventilated with $100 \%$ inspired $\mathrm{O}_{2}(42 \pm 4.4 \mathrm{~mm} \mathrm{Hg})$ and $21 \%$ inspired $\mathrm{O}_{2}(44 \pm 3.8 \mathrm{~mm}$ $\mathrm{Hg}$ ) (Figure 5b). No difference was seen in mean pulmonary artery pressure between asphyxiated variable $\mathrm{FIO}_{2}$ group and controls. There were no significant differences in pulmonary vascular resistance among the asphyxiated lambs (data not shown).

\section{DISCUSSION}

To our knowledge, this is the first study to evaluate pulmonary and systemic hemodynamics during resuscitation using the new preductal $\mathrm{SpO}_{2}$ target guidelines (13) in a model of perinatal asphyxia with lung disease. This study demonstrates that initiating resuscitation with $21 \%$ oxygen and titrating inspired oxygen based on preductal $\mathrm{SpO}_{2}$ in asphyxiated lambs results in hemodynamic changes similar to that achieved with room air in healthy lambs.

Baseline preductal $\mathrm{SpO}_{2}$ at initiation of resuscitation in most nonasphyxiated neonates is in the 50 s and $60 \mathrm{~s}(5,14,15)$. However, $\mathrm{HR}$ and $\mathrm{SpO}_{2}$ are significantly lower in severely asphyxiated neonates similar to the lambs in our study. It is encouraging to note that $\mathrm{SpO}_{2}$ and $\mathrm{HR}$ can be restored to "normal" range by $60 \mathrm{~s}$ of effective positive pressure ventilation (Figures 1 and 5) with 21\% inspired oxygen.

Studies evaluating inspired oxygen in asphyxiated animal models have shown that resuscitation with $21 \%$ oxygen is adequate to induce pulmonary vasodilation and "return of spontaneous circulation" (8,16-19). However, none of these animal models had lung disease and had low alveolar-arterial oxygen gradient $\left(\mathrm{AaDO}_{2}\right)$. Hence resuscitation with $21 \%$ oxygen was probably adequate to achieve $\mathrm{SpO}_{2}$ in the target range. In the current study, we have used a model with meconium aspiration resulting in elevated $\mathrm{AaDO}_{2}(264 \pm 37$ in asphyxiated lambs and $69 \pm 11 \mathrm{~mm} \mathrm{Hg}$ in control lambs) secondary to ventilation-perfusion mismatch and pulmonary hypertension (9). Resuscitation with $21 \%$ oxygen alone in this model did not achieve target $\mathrm{SpO}_{2}$ (Figure 1) and limited the increase in pulmonary blood flow (Figure 6a). Adjusting $\mathrm{FIO}_{2}$ significantly improved $\mathrm{SpO}_{2}$ and pulmonary blood flow compared to the $21 \%$ oxygen resuscitation.

Why was pulmonary blood flow lower in asphyxiated lambs resuscitated with $21 \%$ oxygen and controls? We have previously shown that a preductal $\mathrm{SpO}_{2}$ of approximately $\geq 90 \%$ is necessary to achieve optimal pulmonary vasodilation in lambs after birth (20,21). Only one asphyxiated lamb (out of six) in the $21 \%$ oxygen resuscitation group achieved $\mathrm{SpO}_{2}>90 \%$ (Figure 1) and could have led to suboptimal pulmonary vasodilation (Figure 6a). In contrast, 15/18 lambs in the variable $\mathrm{FIO}_{2}$ category achieved $\mathrm{SpO}_{2}>90 \%$. In addition, metabolic acidosis is known to decrease the threshold for hypoxic pulmonary vasoconstriction (22) and could have contributed to reduced pulmonary vasodilation in response to room air resuscitation in this study. We have shown in the past that maintaining $\mathrm{PaO}_{2}$ between 45 and $65 \mathrm{~mm} \mathrm{Hg}$ is necessary to avoid hypoxic pulmonary vasoconstriction and does not increase pulmonary arterial contractility (23). Our control lambs had an average $\mathrm{PaO}_{2}$ of $34 \pm 8 \mathrm{~mm} \mathrm{Hg}$ at $10 \mathrm{~min}$ and reached $49 \pm 6 \mathrm{~mm} \mathrm{Hg}$ by $15 \mathrm{~min}$. These low (albeit physiologic) $\mathrm{PaO}_{2}$ values could have contributed to lower Qp in lambs resuscitated with 21\% oxygen. 


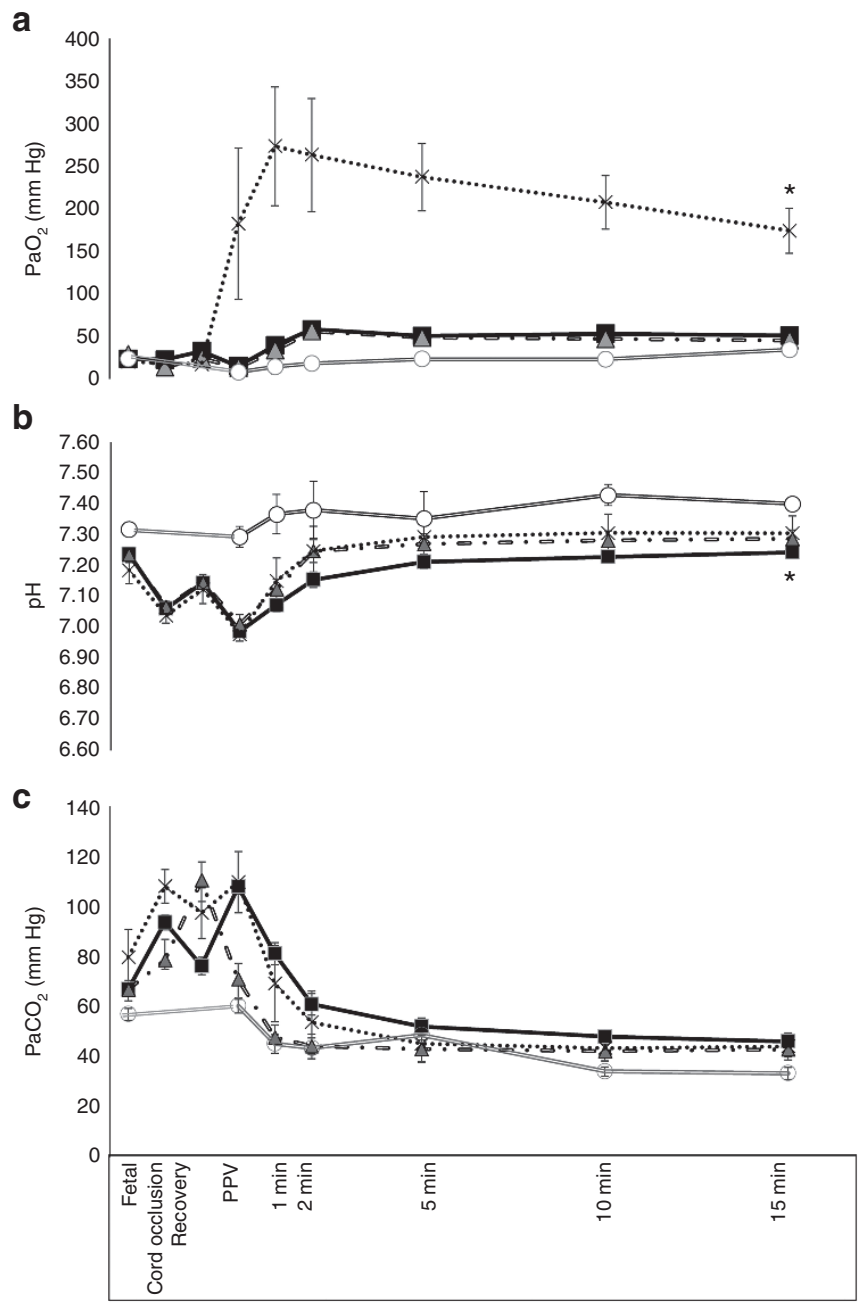

Figure 3. Partial pressure of oxygen in preductal right carotid arterial blood $\left(\mathrm{PaO}_{2^{\prime}}\right.$ panel $\mathbf{a}$ ), arterial $\mathrm{pH}$ (panel $\mathbf{b}$ ), and partial pressure of $\mathrm{CO}_{2}$ in arterial blood $\left(\mathrm{PaCO}_{2}\right.$, panel c) during the first $15 \mathrm{~min}$ of postnatal age in control lambs (open circle) and asphyxiated term lambs ventilated with $21 \% \mathrm{O}_{2}$ (gray triangle), $100 \% \mathrm{O}_{2}$ (cross), and inspired oxygen $\left(\mathrm{FIO}_{2}\right.$ ) titrated to keep the $\mathrm{SpO}_{2}$ as per Neonatal Resuscitation Program guidelines (black square). ${ }^{*} P<0.05, \mathrm{PaO}_{2}$ in $100 \% \mathrm{O}_{2}$ group is significantly higher than all other groups throughout the resuscitation period. PPV, positive pressure ventilation.

Recently, Kapadia et al. performed a novel clinical study to evaluate inspired oxygen titrated based on preductal $\mathrm{SpO}_{2}$ in preterm neonates (24). Low oxygen strategy in this study was similar to the variable $\mathrm{FIO}_{2}$ arm in the current study. Compared to $100 \%$ oxygen resuscitation, low $\mathrm{O}_{2}$ strategy was associated with lower bronchopulmonary dysplasia. Our study demonstrates that $21 \%$ oxygen alone may not be adequate to induce pulmonary vasodilation in asphyxiated neonates with lung disease. We also demonstrate that adjusting $\mathrm{FIO}_{2}$ based on preductal $\mathrm{SpO}_{2}$ leads to pulmonary vasodilation similar to $100 \%$ oxygen resuscitation with considerably less oxygen exposure.

Resuscitation with $100 \%$ oxygen did not result in higher pulmonary blood flow compared to resuscitation with variable $\mathrm{FIO}_{2}$. Clinical and translational studies $(23,25)$ have

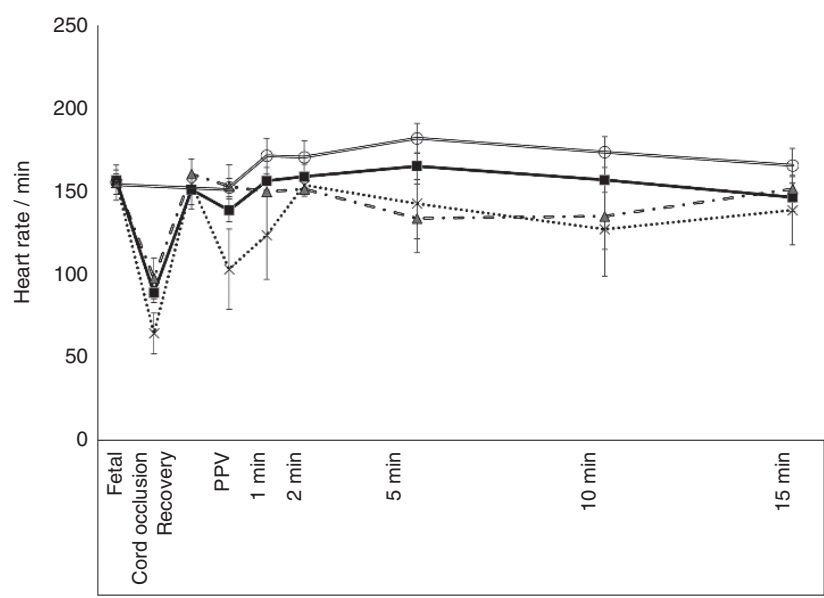

Figure 4. Variation in heart rate (beats per minute) in the first $15 \mathrm{~min}$ of life in control lambs (open circle) and asphyxiated term lambs ventilated with $21 \% \mathrm{O}_{2}$ (gray triangle), $100 \% \mathrm{O}_{2}$ (cross), and inspired oxygen $\left(\mathrm{FIO}_{2}\right)$ titrated to keep the $\mathrm{SpO}_{2}$ between 85 and $95 \%$ (black square). PPV, positive pressure ventilation.
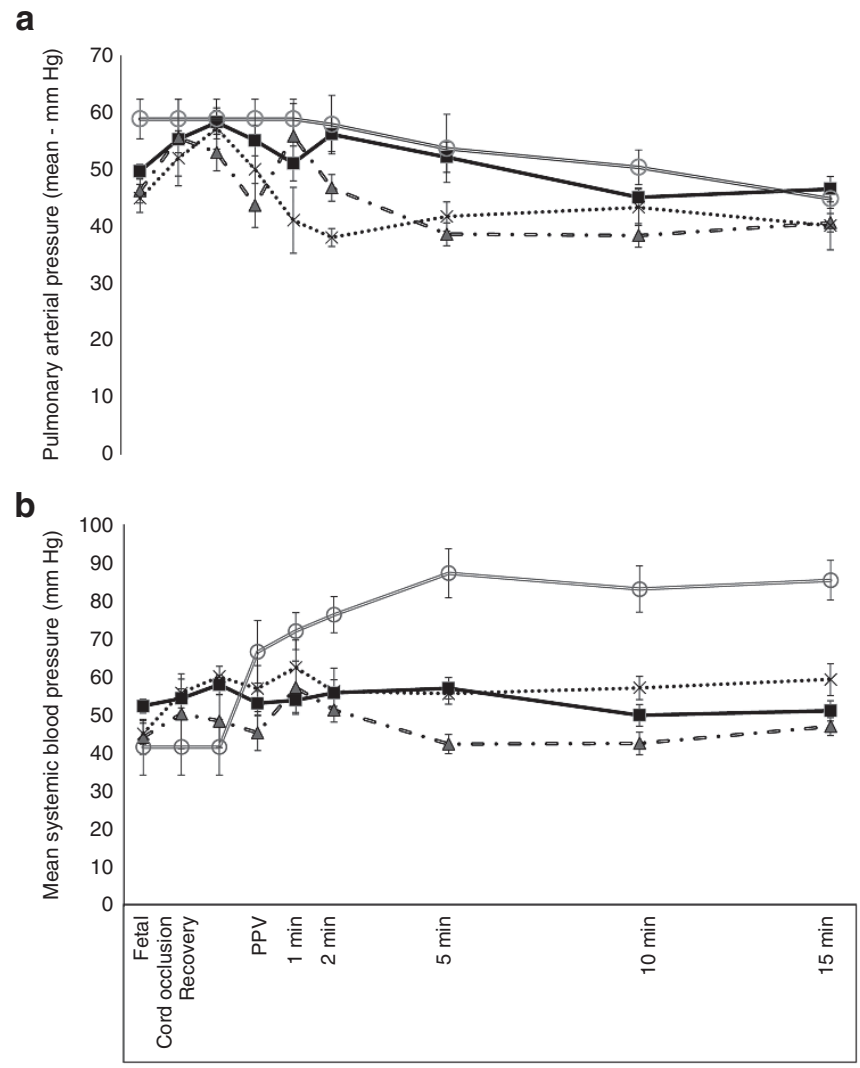

Figure 5. Mean systemic arterial pressure (panel a) and mean pulmonary blood pressure (panel b) during the first $15 \mathrm{~min}$ of postnatal age in control lambs (open circle) and asphyxiated term lambs ventilated with $21 \% \mathrm{O}_{2}$ (gray triangle), $100 \% \mathrm{O}_{2}$ (cross), and inspired oxygen ( $\mathrm{FIO}_{2}$ ) titrated to keep the $\mathrm{SpO}_{2}$ as per Neonatal Resuscitation Program guidelines (black square). PPV, positive pressure ventilation.

demonstrated increased oxidative stress following resuscitation with $100 \%$ oxygen leading to increased pulmonary vasoconstriction (23). We speculate that resuscitation with variable 


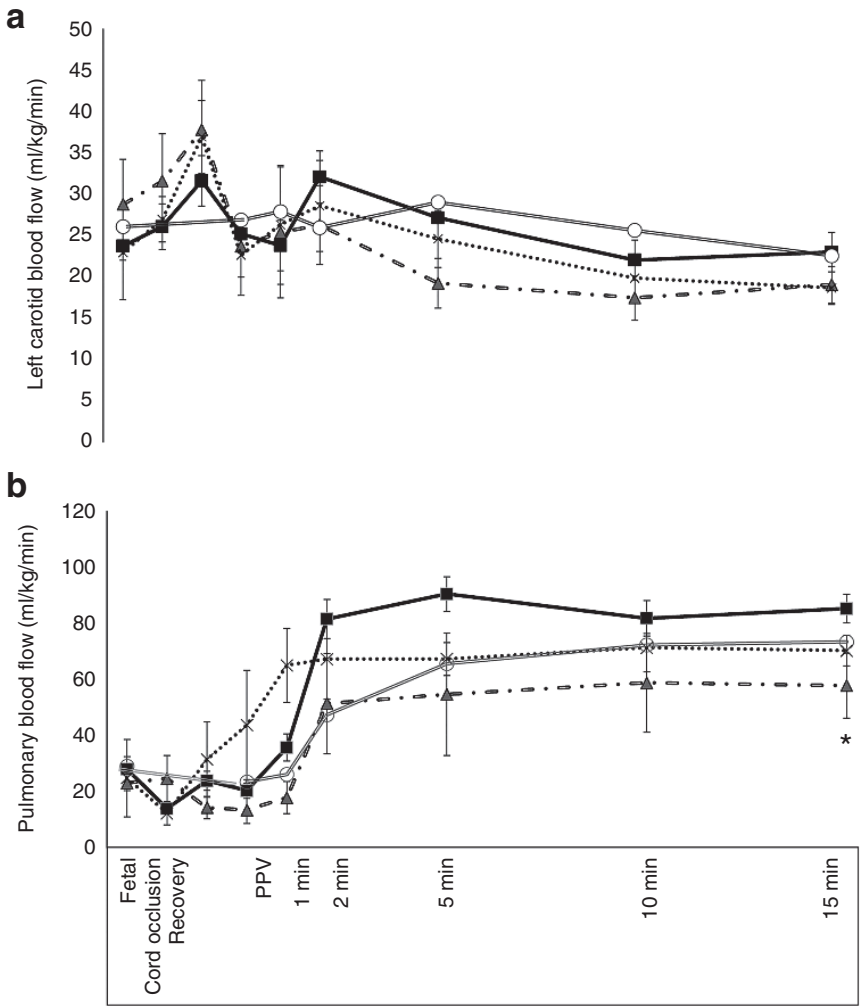

Figure 6. Variation in carotid blood flow (Qca, panel a) and pulmonary blood flow (Qp, panel b) in the first $15 \mathrm{~min}$ of postnatal age in control lambs (open circle) and asphyxiated term lambs ventilated with $21 \% \mathrm{O}_{2}$ (gray triangle), $100 \% \mathrm{O}_{2}$ (cross), and inspired oxygen $\left(\mathrm{FIO}_{2}\right.$ ) titrated to maintain preductal $\mathrm{SpO}_{2}$ as per Neonatal Resuscitation Program guidelines (black square). ${ }^{*} P<0.05$ by ANOVA ( $21 \%$ asphyxiated and controls significantly lower than variable $\mathrm{FIO}_{2}$ asphyxia by Bonferroni post hoc test). PPV, positive pressure ventilation.

$\mathrm{FIO}_{2}$ resulted in an optimal balance between oxygen-mediated pulmonary vasodilation and oxygen free radical-induced vasoconstriction.

Adjusting $\mathrm{FIO}_{2}$ to achieve target $\mathrm{SpO}_{2}$ requires additional personnel and equipment. In the current study, an additional neonatal provider (a total of four resuscitators) was required to closely monitor $\mathrm{SpO}_{2}$ and adjust $\mathrm{FIO}_{2}$. Absence of adequate providers during resuscitation may limit personnel availability to perform this function. In addition, many delivery suites/ birthing rooms in level I nurseries in the United States and nurseries in developing countries are not equipped with oxygen blenders and pulse oximeters. Current clinical literature $(26,27)$ and results from our study clearly indicate that resuscitation and effective ventilation of the lungs with $21 \%$ oxygen improves HR and systemic blood pressure and decreases pulmonary vascular resistance in a model of severe asphyxia, acidosis, and lung disease. Based on these results, if resources are limited during resuscitation of a severely asphyxiated neonate, the initial focus should be on effective ventilation of the lungs with room air and monitoring HR.

Recent evidence suggests that initiation of resuscitation and ventilation of the lungs before clamping the cord results in stable cerebral blood flow and influence $\mathrm{SpO}_{2}$ and oxygen delivery to the brain $(28,29)$. Further studies to evaluate the impact of delayed cord clamping and ventilation before cord clamping on $\mathrm{SpO}_{2}$ during resuscitation are warranted.

There are several limitations to this study. All lambs were intubated prior to delivery. Mask ventilation and the process of emergent intubation after delivery may result in lower $\mathrm{SpO}_{2}$ values and were not evaluated in this study. The severity of lung disease, pulmonary hypertension, and hypoxemic respiratory failure was moderate (with oxygenation index in the mid-20s). Very severe persistent pulmonary hypertension of the newborn and profound hypoxemia may result in much higher oxygen requirement. A fixed positive end expiratory pressure of $5 \mathrm{~cm} \mathrm{H}_{2} \mathrm{O}$ was adapted in this study. A higher positive end expiratory pressure or use of sustained inflation may have established functional residual capacity earlier leading to lower $\mathrm{FIO}_{2}$ requirement (30). Finally, this model only evaluates short-term acute lung injury. Long-standing asphyxial insult and lung injury, as seen in meconium aspiration, may lead to vascular remodeling and fixed pulmonary hypertension. Finally, we did not euthanize the lambs at the end of $15 \mathrm{~min}$ of resuscitation to evaluate oxidant injury to the lungs (as we did in our previous study) (8). As the lambs were part of a different study to evaluate optimal $\mathrm{SpO}_{2}$ target at term gestation, we continued to ventilate them for $6 \mathrm{~h}$.

In conclusion, adjusting $\mathrm{FIO}_{2}$ to maintain preductal $\mathrm{SpO}_{2}$ in the target range recommended by NRP, in asphyxiated lambs with lung disease, results in pulmonary hemodynamics similar to that observed in control nonasphyxiated lambs with normal lungs. However, in resource-limited and emergent situations, effective ventilation of the lungs with $21 \%$ oxygen leading to increased HR may be a reasonable approach as well. Clinical studies evaluating the efficacy of these recommendations are warranted.

\section{METHODS}

This study was approved by the Institutional Animal Care and Use Committee (IACUC) at State University of New York at Buffalo. Time-dated pregnant ewes (139-142 d gestation; term $145 \mathrm{~d}$ ) (New Life Pastures, Attica, NY) were sedated, intubated, and ventilated with $2 \%$ isoflurane. Cesarean section was performed and the fetal lamb was partially exteriorized. Jugular and carotid lines were placed on the right side for access, preductal arterial blood gas sampling, and blood pressure monitoring. Catheters were placed in the main pulmonary artery and left atrium for pressure monitoring as previously described $(20,21)$. Fetal lambs were asphyxiated by umbilical cord occlusion and meconium $(5 \mathrm{ml} / \mathrm{kg}$ of $20 \%$ meconium suspended in ewe amniotic fluid) was instilled into their endotracheal tube as previously described (9). The lambs were then delivered, ventilated, and blood gases were obtained at fetal (predelivery), delivery, $1 \mathrm{~min}, 2 \mathrm{~min}$, $5 \mathrm{~min}, 10 \mathrm{~min}$, and $15 \mathrm{~min}$. Thirty lambs were randomized into three groups (using sealed envelopes at 1:1:3 ratio): (i) $\mathrm{FIO}_{2} 1$; (ii) $\mathrm{FIO}_{2} 0.21$, irrespective of $\mathrm{SpO}_{2}$; and (iii) initial $\mathrm{FIO}_{2}$ of 0.21 , titrated to keep preductal $\mathrm{SpO}_{2}$ in the target range recommended by NRP (31). In group 3 , attempts were made to maintain preductal $\mathrm{SpO}_{2}$ between 60 and $65 \%$ in the first minute, 65 and $70 \%$ in the second minute, 70 and $75 \%$ in the third minute, 75 and $80 \%$ in the fourth minute, 80 and $85 \%$ in the fifth minute, and 85 and $95 \%$ between 5 and 15 min of postnatal age as per NRP guidelines. If preductal $\mathrm{SpO}_{2}$ was outside this range, inspired oxygen was adjusted by $5 \%$ every $15 \mathrm{~s}$ by an attending neonatologist/neonatology fellow. Initial ventilation settings were peak inspiratory pressure of $30 \mathrm{~cm} \mathrm{H} \mathrm{H}_{2} \mathrm{O}$, positive end expiratory pressure $-5 \mathrm{~cm} \mathrm{H_{2 }} \mathrm{O}$ and rate $-40 / \mathrm{min}$. Subsequent ventilation was adjusted using blood gas values. 


\section{Articles | Rawatet al.}

The randomization described in the previous paragraph was part of a larger study where the variable $\mathrm{FIO}_{2}$ group was further managed between $15 \mathrm{~min}$ and $6 \mathrm{~h}$ of postnatal age with different $\mathrm{SpO}_{2}$ ranges (85-89\%, 90-94\%, and 95-99\%). The second portion of the experiment (from $15 \mathrm{~min}$ to $6 \mathrm{~h}$ ) is not described in this manuscript. Lambs were ventilated for $6 \mathrm{~h}$ and then sacrificed. For controls, seven healthy (nonasphyxiated) term lambs without lung disease were ventilated with $21 \% \mathrm{O}_{2}$ irrespective of $\mathrm{SpO}_{2}$. Pulmonary and systemic hemodynamic parameters were compared between the groups.

\section{STATEMENT OF FINANCIAL SUPPORT}

This work was supported by American Academy of Pediatrics, Neonatal Resuscitation Program (to S.L. and M.R.), Elk Grove Village, IL and 1R01HD072929-0 (to S.L.), National Institute of Child Health and Human Development, Bethesda, MD.

Disclosure: No financial ties to products in the study or potential/perceived conflicts of interest.

\section{REFERENCES}

1. Kattwinkel J. Textbook of Neonatal Resuscitation. 5th edn. Elk Grove Village, IL: American Academy of Pediatrics, 2006.

2. Kattwinkel J. Textbook of Neonatal Resuscitation. 6th edn. Elk Grove Village, IL: American Academy of Pediatrics, 2011.

3. Kattwinkel J, Perlman JM, Aziz K, et al. Part 15: neonatal resuscitation: 2010 American Heart Association Guidelines for Cardiopulmonary Resuscitation and Emergency Cardiovascular Care. Circulation 2010;122:Suppl 3:S909-19.

4. Perlman JM, Wyllie J, Kattwinkel J, et al.; Neonatal Resuscitation Chapter Collaborators. Part 11: neonatal resuscitation: 2010 International Consensus on Cardiopulmonary Resuscitation and Emergency Cardiovascular Care Science With Treatment Recommendations. Circulation 2010;122:16 Suppl 2:S516-38.

5. Dawson JA, Kamlin CO, Vento M, et al. Defining the reference range for oxygen saturation for infants after birth. Pediatrics 2010;125:e1340-7.

6. Saugstad OD. Delivery room management of term and preterm newly born infants. Neonatology 2015;107:365-71.

7. Saugstad OD; International Liason Committee on Resuscitation. New guidelines for newborn resuscitation-a critical evaluation. Acta Paediatr 2011;100:1058-62.

8. Lakshminrusimha S, Steinhorn RH, Wedgwood S, et al. Pulmonary hemodynamics and vascular reactivity in asphyxiated term lambs resuscitated with 21 and 100\% oxygen. J Appl Physiol (1985) 2011;111:1441-7.

9. Lakshminrusimha S, Mathew B, Nair J, et al. Tracheal suctioning improves gas exchange but not hemodynamics in asphyxiated lambs with meconium aspiration. Pediatr Res 2015;77:347-55.

10. Lapointe A, Barrington KJ. Pulmonary hypertension and the asphyxiated newborn. J Pediatr 2011;158:Suppl 2:e19-24.

11. Nair J, Lakshminrusimha S. Update on PPHN: mechanisms and treatment. Semin Perinatol 2014;38:78-91.

12. Wyckoff MH. Respiratory and cardiovascular support in the delivery room. In: Bancalari E, Polin RA, eds. The Newborn Lung. 2nd edn. Philadelphia, PA: Elsevier Saunders, 2012:247-64.
13. Kattwinkel J, Perlman JM, Aziz K, et al.; American Heart Association. Neonatal resuscitation: 2010 American Heart Association Guidelines for Cardiopulmonary Resuscitation and Emergency Cardiovascular Care. Pediatrics 2010;126:e1400-13.

14. Dawson JA, Kamlin CO, Wong C, et al. Oxygen saturation and heart rate during delivery room resuscitation of infants $<30$ weeks' gestation with air or 100\% oxygen. Arch Dis Child Fetal Neonatal Ed 2009;94:F87-91.

15. Dawson JA, Morley CJ. Monitoring oxygen saturation and heart rate in the early neonatal period. Semin Fetal Neonatal Med 2010;15:203-7.

16. Proschan MA, Waclawiw MA. Practical guidelines for multiplicity adjustment in clinical trials. Control Clin Trials 2000;21:527-39.

17. Solevåg AL, Dannevig I, Nakstad B, Saugstad OD. Resuscitation of severely asphyctic newborn pigs with cardiac arrest by using $21 \%$ or $100 \%$ oxygen. Neonatology 2010;98:64-72.

18. Linner R, Werner O, Perez-de-Sa V, Cunha-Goncalves D. Circulatory recovery is as fast with air ventilation as with $100 \%$ oxygen after asphyxiainduced cardiac arrest in piglets. Pediatr Res 2009;66:391-4.

19. Perez-de-Sa V, Cunha-Goncalves D, Nordh A, et al. High brain tissue oxygen tension during ventilation with $100 \%$ oxygen after fetal asphyxia in newborn sheep. Pediatr Res 2009;65:57-61.

20. Lakshminrusimha S, Russell JA, Steinhorn RH, et al. Pulmonary hemodynamics in neonatal lambs resuscitated with $21 \%, 50 \%$, and $100 \%$ oxygen. Pediatr Res 2007;62:313-8.

21. Lakshminrusimha S, Swartz DD, Gugino SF, et al. Oxygen concentration and pulmonary hemodynamics in newborn lambs with pulmonary hypertension. Pediatr Res 2009;66:539-44.

22. Rudolph AM, Yuan S. Response of the pulmonary vasculature to hypoxia and $\mathrm{H}^{+}$ion concentration changes. J Clin Invest 1966;45:399-411.

23. Lakshminrusimha S, Russell JA, Steinhorn RH, et al. Pulmonary arterial contractility in neonatal lambs increases with $100 \%$ oxygen resuscitation. Pediatr Res 2006;59:137-41.

24. Kapadia VS, Chalak LF, Sparks JE, Allen JR, Savani RC, Wyckoff MH. Resuscitation of preterm neonates with limited versus high oxygen strategy. Pediatrics 2013;132:e1488-96.

25. Vento M, Asensi M, Sastre J, García-Sala F, Pallardó FV, Viña J. Resuscitation with room air instead of $100 \%$ oxygen prevents oxidative stress in moderately asphyxiated term neonates. Pediatrics 2001;107:642-7.

26. Saugstad OD, Ramji S, Soll RF, Vento M. Resuscitation of newborn infants with $21 \%$ or $100 \%$ oxygen: an updated systematic review and metaanalysis. Neonatology 2008;94:176-82.

27. Vento M, Saugstad OD. Resuscitation of the term and preterm infant. Semin Fetal Neonatal Med 2010;15:216-22.

28. Bhatt S, Alison BJ, Wallace EM, et al. Delaying cord clamping until ventilation onset improves cardiovascular function at birth in preterm lambs. J Physiol 2013;591:Pt 8:2113-26.

29. Lakshminrusimha S, Van Meurs K. Better timing for cord clamping is after onset of lung aeration. Pediatr Res 2015;77:615-7.

30. Klingenberg C, Sobotka KS, Ong T, et al. Effect of sustained inflation duration; resuscitation of near-term asphyxiated lambs. Arch Dis Child Fetal Neonatal Ed 2013;98:F222-7.

31. Morin FI. Hyperventilation, alkalosis, prostaglandins and the pulmonary circulation of the newborn. Appl Physiol 1986;61:2088-94. 